\title{
Evaluation of the expression and clinical value of IncRNA AC010761.9 in human gastric adenocarcinoma
}

\author{
Zhihua Wang ${ }^{1,2,5}$, Kai Wang ${ }^{1,2}$, Yuan Dang ${ }^{1,2}$, Xiaojuan Ouyang ${ }^{1,2}$, Fan Zhang ${ }^{1,2}$, Wenyuan Wang ${ }^{3,4}$, Lie Wang ${ }^{3,4^{*}}$ \\ and Qiaojia Huang ${ }^{1,2^{*}}$
}

\begin{abstract}
Background: The current study determined the expression and clinical value of IncRNA AC010761.9 in human gastric adenocarcinoma (GA).

Methods: Real-time quantitative reverse transcription (qRT)-PCR was used to detect the level of IncRNA expression in 145 GA tissues and three GA cell lines, and the correlation between its level and clinicopathologic characteristics and potential corresponding mRNA of TNF receptor-associated factor 4 gene (TRAF4) was then evaluated.

Results: Elevated IncRNA AC010761.9 was detected in all 6 GA tissues by previous IncRNA expression profile microarray assay. LncRNA AC010761.9 was over-expressed in 99 of 145 GA tissues (68.3\%) with an elevated fold change of up to 35.14 compared to matched paracancerous tissues $(p<0.05)$, and was also over-expressed in the 3 GA cell lines (MGC803, BGC823, and SGC7901) compared to the normal gastric mucosal epithelial cell line (GES-1 cells; $p<0.05)$ by qRT-PCR. The elevated expression of this IncRNA was related to tumor size $(p=0.028)$, degree of differentiation $(p=0.047)$, and serum carbohydrate antigen (CA19-9) and carcinoembryonic antigen (CEA) concentrations ( $p=0.026$ and $p=0.037$, respectively). Multivariate analysis further confirmed that the expression of IncRNA AC010761.9 was related to the degree of tumor differentiation $(p=0.015)$. Additionally, the expression of InCRNA AC010761.9 had a positive correlation with the mRNA expression of the potentially associated gene (TRAF4) in GA tissues $(r=0.385, p<0.01)$.
\end{abstract}

Conclusions: LnCRNA AC010761.9 may be linked to GA progression and is a potential new biomarker for GA.

Keywords: Gastric adenocarcinoma, IncRNA AC010761.9, Expression and clinical value

\section{Background}

Globally, gastric cancer is one of the most common malignant tumors affecting the human digestive tract [1]. Gastric cancer is also one of the major leading causes of cancer-related deaths worldwide [1]. Moreover, patients with advanced-stage gastric cancer frequently die. This malignant illness can occur at any age; however, gastric cancer usually affects the elderly. Data from cancer epidemiologic investigations have shown that the incidence of gastric cancer has a trend towards younger

\footnotetext{
* Correspondence: fzptwk@xmu.edu.cn; huangqj100@126.com

${ }^{3}$ Department of General Surgery, Fuzong Clinical Medical College, Fujian Medical University, Fuzhou, China

'Department of Experimental Medicine, Fuzong Clinical Medical College, Fujian Medical University, Fuzhou, China

Full list of author information is available at the end of the article
}

patients in recent years, thus it is important to find more effective and available biomarkers to further understand the pathogenesis of gastric cancer and to guide therapeutic decisions. Cancer biomarkers are closely related to the features present in malignant cells, which often exhibit great value in reflecting the occurrence and development of the tumor or monitoring the tumor response to treatment [2]. If biomarkers for DNA, RNA, and protein can be used clinically, the features of the malignancies from multiple levels will be demonstrated and may be of importance in guiding therapy. An evaluation of potential new biomarkers will help reach the above mentioned goals.

Recent studies have shown that long non-coding RNAs (lncRNAs) are closely related to a variety of human cancer 
occurrence and development [3-5]. LncRNAs are RNAs without a function on coding proteins and are named based on length (i.e., > 200 nucleotides) [6]. The roles for lncRNAs in cancer have attracted attention in the past several years, and many studies have reported that lncRNAs are a new class of biomarkers for human cancers, including gastric cancer [3, 7]. Emerging evidence has shown that gastric cancer occurrence and progression are accompanied by alterations in lncRNA expression or function $[8,9]$, so lncRNAs have been shown to be able to serve as biomarkers for the diagnosis and/or therapy of gastric cancer [10]; however, the actual number of lncRNAs related to gastric cancer is unknown.

LncRNA AC010761.9 is a natural antisense lncRNA which has a length of 521 nucleotides and does not have a function to translate protein. This lncRNA is located on human chromosome 17, and the potentially associated gene of this IncRNA is thought to be TNF receptorassociated factor (TRAF) 4, a gene which is able to promote cancer development via different molecular mechanisms $[11,12]$. According to the results from our previous lncRNA expression profile chip assay, lncRNA AC010761.9 was identified to be up-regulated in all six gastric adenocarcinoma (GA) tissues compared to the levels in the matched paracancerous tissues. No studies have been conducted on this IncRNA with gastric cancer previously, so this lncRNA was selected for further investigation in this work. GA is a primary malignant tumor of the stomach. Therefore, in the present study, lncRNA AC010761.9 expression in 145 GA tissues and the matched paracancerous tissues and in three different GA cell lines (BGC-823, SGC-7901, and MGC-803 cells) was determined, and the clinical value was evaluated according to the levels of expression and clinicopathologic factors. In addition, the relationship between lncRNA AC010761.9 and TRAF4 mRNA expression in 78 samples and three GA cell lines was then investigated.

\section{Methods}

Collection of GA tissue specimens

One hundred forty-five fresh GA tissues were collected at Fuzhou General Hospital in Fujian, China, between March 2014 and October 2015. This group of patients included 145 patients, all of whom had a definite diagnosis of primary GA. The tissue samples, including GA and the matched paracancerous tissues $(5 \mathrm{~cm}$ from the lesion), were obtained immediately after the surgical procedure, which was performed to remove the primary GA, kept in RNAlater (Qiagen, Duesseldorf, Germany), and stored at $-80{ }^{\circ} \mathrm{C}$ before use. The histopathologic diagnosis, the staging tumor-node-metastasis (TNM), and the determination of the histologic grade were performed by two pathologists working in the Department of Pathology of Fuzhou General Hospital (Fujian,
China) according to the International Union Against Cancer (5th edition) and the guidelines of the National Comprehensive Cancer Network (NCCN) Clinical Practice of Oncology (V.1.2011) [13]. No pre-operative chemotherapy or radiotherapy was administered. The clinical and pathologic data of this group of patients were also collected and were shown in Table 1. (Except patients in the subgroup related with tumor location only had 125 cases with detailed clinical information, other subgroups had 129 patients with detailed clinical information).

\section{Preparation of GA tissue specimens for the immunohistochemical assay}

The immunohistochemical (IHC) assay used paraffinembedded tissue samples, which were made using the same fresh tissue samples described above and performed by two pathologists.

\section{Collection of serum samples}

The serum samples from the same patients were collected by laboratory technicians prior to surgery and used for measurement of the levels of digestive tract malignant tumor markers (AFP, CEA, and CA19-9).

\section{LncRNA expression profile microarray chip assay}

The results from the Human LncRNA Expression Profile Microarray V3.0 (Arraystar, Rockville, MD, USA) were obtained from the previous work and completed by Kang Chen Bio-tech (Shanghai, China) based on the manufacturer's instructions [13]. Microarray assay and data analysis were performed, from which the differentially expressed lncRNAs and mRNAs from six GA tissues and the matched paracancerous tissues were identified [13], by KangChen Bio-tech [13].

\section{Culture of GA and normal gastric epithelial cells}

The three GA cell lines used in the current study were BGC-823, SGC-7901, and MGC-803. BGC-823 and MGC-803 were obtained from the Shanghai Institute of Biochemistry of the Chinese Academy of Sciences in Shanghai, China, and SGC-7901 was obtained from the American Type Culture Collection (Manassas, VA, USA). The normal cell line used in this work was the GES-1 cell line, which was a normal human gastric mucosal epithelial cell line, and was purchased from the Beijing Cancer Institute (Beijing, China). The cells were cultured in RPMI1640 medium (for BGC-823, SGC-7901, and MGC-803 cells) and Dulbecco's modified Eagle's medium (for GES-1 cells; Invitrogen, Grand Island, NY, USA) based on our previously reported methods [13].

\section{Isolation of total RNA and performance of qRT-PCR}

Both the total RNA from the tissues and cultured cells were extracted with the TransZol Up Plus RNA Kit 
Table 1 Relationships between IncRNA AC010761.9 expression $(\Delta \mathrm{Ct}$ value) and patient clinical pathologic factors and serum tumor markers

\begin{tabular}{|c|c|c|c|}
\hline Characteristics & No. of case (\%) & Mean \pm SD & $p$ value \\
\hline \multicolumn{4}{|l|}{ Age } \\
\hline$\geq 60$ & $70(54.2)$ & $19.08 \pm 2.904$ & \multirow[t]{2}{*}{0.162} \\
\hline$<60$ & $59(45.8)$ & $18.31 \pm 3.309$ & \\
\hline \multicolumn{4}{|l|}{ Gender } \\
\hline Male & $102(79.1)$ & $18.66 \pm 3.087$ & \multirow[t]{2}{*}{0.620} \\
\hline Female & $27(20.9)$ & $18.99 \pm 3.227$ & \\
\hline \multicolumn{4}{|l|}{ Tumor location } \\
\hline Upper & $35(28.0)$ & $19.33 \pm 3.198$ & \multirow[t]{3}{*}{0.621} \\
\hline Middle & $48(38.4)$ & $18.52 \pm 3.062$ & \\
\hline Lower & 42 (33.6) & $18.68 \pm 3.140$ & \\
\hline \multicolumn{4}{|l|}{ Diameter } \\
\hline$\geq 4$ & $70(54.2)$ & $19.28 \pm 2.967$ & \multirow[t]{2}{*}{0.028} \\
\hline$<4$ & $59(45.8)$ & $18.07 \pm 3.167$ & \\
\hline \multicolumn{4}{|l|}{ Differentiation } \\
\hline Poor & $97(75.2)$ & $18.48 \pm 3.096$ & \multirow[t]{3}{*}{0.047} \\
\hline Moderate & $30(23.2)$ & $19.73 \pm 2.966$ & \\
\hline Well & $2(1.6)$ & $15.39 \pm 1.478$ & \\
\hline \multicolumn{4}{|l|}{ Invasion } \\
\hline $\mathrm{T} 1$ & $11(8.5)$ & $18.08 \pm 3.155$ & \multirow[t]{4}{*}{0.269} \\
\hline $\mathrm{T} 2$ & $11(8.5)$ & $18.76 \pm 4.302$ & \\
\hline T3 & $14(10.8)$ & $17.36 \pm 3.074$ & \\
\hline T4 & $93(72.2)$ & $19.01 \pm 2.931$ & \\
\hline \multicolumn{4}{|c|}{ Lymphatic metastasis } \\
\hline No & $32(24.8)$ & $18.98 \pm 3.274$ & \multirow[t]{2}{*}{0.597} \\
\hline$N 1-3$ & $97(75.2)$ & $18.64 \pm 3.063$ & \\
\hline \multicolumn{4}{|l|}{ Venous invasion } \\
\hline Absent & $71(55)$ & $18.67 \pm 3.184$ & \multirow[t]{2}{*}{0.808} \\
\hline Present & $58(45)$ & $18.80 \pm 3.037$ & \\
\hline \multicolumn{4}{|c|}{ Perineural invasion } \\
\hline Absent & $59(45.7)$ & $18.51 \pm 3.243$ & \multirow[t]{2}{*}{0.399} \\
\hline Present & $70(54.3)$ & $18.98 \pm 2.946$ & \\
\hline \multicolumn{4}{|l|}{ CEA } \\
\hline Normal & $109(84.5)$ & $18.48 \pm 2.935$ & \multirow[t]{2}{*}{0.037} \\
\hline High & $20(15.5)$ & $20.05 \pm 3.727$ & \\
\hline \multicolumn{4}{|l|}{ CA19-9 } \\
\hline Normal & $113(87.5)$ & $18.50 \pm 2.999$ & \multirow[t]{2}{*}{0.026} \\
\hline High & $16(12.5)$ & $20.34 \pm 3.469$ & \\
\hline \multicolumn{4}{|l|}{ AFP } \\
\hline Normal & $121(93.8)$ & $18.64 \pm 3.082$ & \multirow[t]{2}{*}{0.248} \\
\hline High & $8(6.2)$ & $19.96 \pm 3.444$ & \\
\hline
\end{tabular}

The italicized values are significant at $p<0.05$
(Transgen Biotech Company, Beijing, China) according to the instructions provided by the manufacturer. Reverse transcription of mRNA into cDNA was then performed with a GoScript ${ }^{\mathrm{tm}}$ Reverse Transcription System (Promega, Madison, WI, USA) according to the instructions provided by the manufacturer. Amplification of the products with the SYBR Green Mix kit (GoTaq ${ }^{\circ}$ qPCR Master Mix; Promega) was carried out in a 2720 Thermal Cycler PCR System (ABI, Grand Island, NY, USA). The primers used in the amplification included that for internal reference 18s RNA, lncRNA AC010761.9, and TRAF4 mRNA, which were as follows: forward $5^{\prime}$ GTAACCCGTTGAACCCCATT-3' and reverse 5' ${ }^{\prime}$-CCAT CCAATCGGTAGTAGCG-3' (for 18s RNA); forward 5' GAGGGAACACTTCTTGCGGG-3' and reverse 5' - CAG GGCCAGTGTCAACCAAA-3' (for lncRNA AC010761.9); and forward 5'-CCACCGTTTCTGCGATACCT-3' and reverse 5'-GGGTCTGGGTAGATCTTGGC-3' for TRAF4 mRNA. The PCR amplification conditions contained the following three steps: step $1,95.0{ }^{\circ} \mathrm{C}$ for 2 min; step 2, $95.0^{\circ} \mathrm{C}$ for $15 \mathrm{~s}$ and $58^{\circ} \mathrm{C}$ for $40 \mathrm{~s} \mathrm{(total} 40$ cycles); and step 3 (dissociation stage), $95^{\circ} \mathrm{C}$ for $15 \mathrm{~s}, 60^{\circ} \mathrm{C}$ for $15 \mathrm{~s}$, and $95^{\circ}$ $\mathrm{C}$ for $15 \mathrm{~s}$. The cycle threshold $(\mathrm{Ct})$ values of $18 \mathrm{~s}$ RNA (control), IncRNA AC010761.9, and TRAF4 mRNA were automatically recorded by the machine. The level of lncRNA AC010761.9 and TRAF4 mRNA expression was obtained by calculating the $\Delta \mathrm{Ct}$, which were inversely proportional to the level of expression. Samples with a higher $\Delta \mathrm{Ct}$ meant lower AC010761.9 or TRAF4 expression. The relative fold changes of AC010761.9 or TRAF4 expression in GA tissues versus matched non-GA tissues or in GA cell lines versus normal gastric cell lines (GES-1) were obtained by calculating the formula $\left(2-^{\wedge \wedge} \mathrm{Ct}\right)$. The results were obtained from three independent experiments and expressed as the means $\pm \mathrm{SD}$.

\section{Quantitative examination of serum AFP, CEA, and CA19-9 levels}

Quantitative examinations of serum carcinoembryonic antigen (CEA), carbohydrate antigen 19-9 (CA19-9), and alpha-fetoprotein (AFP) concentrations in 129 patients with GA were part of the routine work-up for GA patients, which were performed by technicians before surgery with the Quantitative Kit for Tumor Marker (Protein Chip-Chemiluminescence; HealthDigit, Huzhou, China) with the HD-2001A ChipReader System (HealthDigit) [13]. Individuals with $<5.0 \mathrm{ng} / \mathrm{ml}$ for CEA, $<35.0 \mathrm{ng} / \mathrm{ml}$ for CA19-9, and $<20.0 \mathrm{ng} / \mathrm{ml}$ for AFP were regarded as having low (normal) expression of the three digestive tract tumor markers.

\section{Immunohistochemical assay}

There were ten immunohistochemical markers to be routinely performed for patients with GA in this hospital 
(vascular endothelial growth factor [VEGF], human epidermal growth factor receptor 2 [C-erbB-2 or HER2], thymidylate synthase [TS], breast cancer 1 [BRCA1], excision repair cross-complementation group 1 [ERCC1], Ki67 antigen [Ki67], ribonucleotide reductase subunit M1 [RRM1], synaptophysin [Syn], neuronal cell adhesion molecule 1 [CD56], and chromogranin A [CgA]). The data were collected from the medical records. The methods, reagents used for IHC assays, and the result determination were the same as previously described [13]. The performances of the IHC assay and result analysis were conducted by pathologists working in this hospital.

\section{Statistical analysis}

SPSS 17 was used for statistical analysis. Data are expressed in the form of mean \pm standard deviation. The comparison between the groups was performed using a $t$ test and one-way ANOVA analysis. The relationship between the levels of IncRNA AC010761.9 and TRAF4 mRNA expression was analyzed using Pearson correlation analysis. Multivariate logistic regression analysis was further used to assess the relationships between lncRNA AC010761.9 expression and patient clinical pathologic factors, and factors used in the multivariate analysis included age, gender, tumor location, diameter, differentiation grade, invasion, lymphatic metastasis, venous invasion, and perineural invasion. Multivariate models did not adjust for that factor which was being tested. A $p<0.05$ was taken as statistically significant.

\section{Results}

\section{LncRNA expression chips showed that IncRNA} AC010761.9 is over-expressed in GA tissues

The lncRNA microarray chip assays were performed in six GA tissues and six matched paracancerous tissues. The results showed that the level of lncRNA AC010761.9 expression was higher in six GA tissues than the matched non-GA tissues (mean increased fold was 2.01, $p<0.05$ ) (Fig. 1). LncRNA AC010761.9 may be a dysregulated lncRNA in GA, thus it was considered to warrant further investigation.

\section{qRT-PCR confirmed that IncRNA AC010761.9 is} over-expressed in GA tissues and cell lines

As depicted in Fig. 2, the results of qRT-PCR further showed that the level of IncRNA AC010761.9 expression was higher in 99 of 145 GA tissues than the matched non-GA tissues, with an over-expressed rate of $68.3 \%(p<0.01)$. When the mean level of expression of this lncRNA in the matched non-GA tissues was taken as 1, an elevated fold up to 35.14 in GA tissues was observed. The results of qRT-PCR also showed that the level of IncRNA AC010761.9 expression was higher in the three GA cell lines (BGC-823, SGC-7901, and MGC-803) compared to normal gastric cells (GES-1 cells; $p<0.05$ ) (Fig. 3). All of these findings indicated that lncRNA AC010761.9 is overexpressed in GA tissues and cell lines.

\section{Relationships between the level of IncRNA AC010761.9 expression and clinical pathologic factors}

Among the 145 patients investigated in the present study, all were diagnosed with GA, and 129 patients had detailed clinical pathologic data. The clinical value of the expression of IncRNA AC010761.9 was then evaluated according to the level of expression and clinical pathologic factors. As depicted in Table 1, the elevated expression of this lncRNA was related with a tumor size $\geq 4$ versus $<4 \mathrm{~cm}(p=0.028)$ and degree of differentiation $(p=0.047)$, but not related with other clinical or pathologic factors, including age, gender, tumor location, lymphatic metastasis, and venous and perineural invasion (Table 1). Data from multivariate analysis further exhibited that IncRNA AC010761.9 expression was related with patient age $(p=0.043)$ and the degree of tumor differentiation $(p=0.015$; Table 2). These results indicated that IncRNA AC010761.9 may be GAassociated lncRNA.

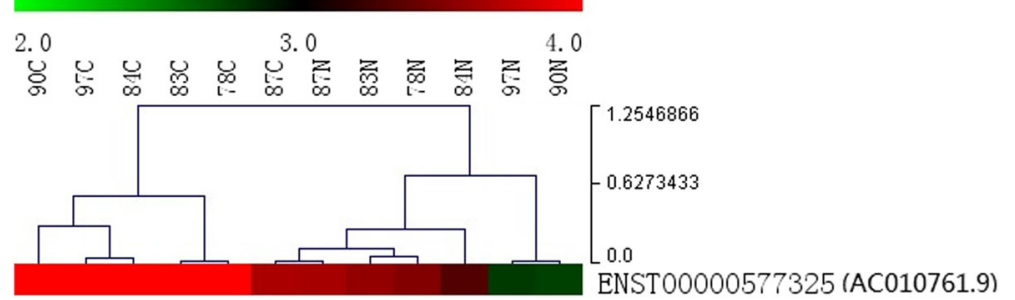

Fig. 1 LncRNA AC010761.9 was over-expressed in GA tissues by IncRNA expression chip assay. $T$ cancer tissues, $N$ matched non-cancer tissues. Cluster analyses from the six GA and their paired non-GA tissues IncRNA chip results showed that LncRNA AC010761.9 was over-expressed in GA tissues compared with that in the paired non-GA tissues (mean increased fold $=2.01$ times, $p<0.05$ ) 


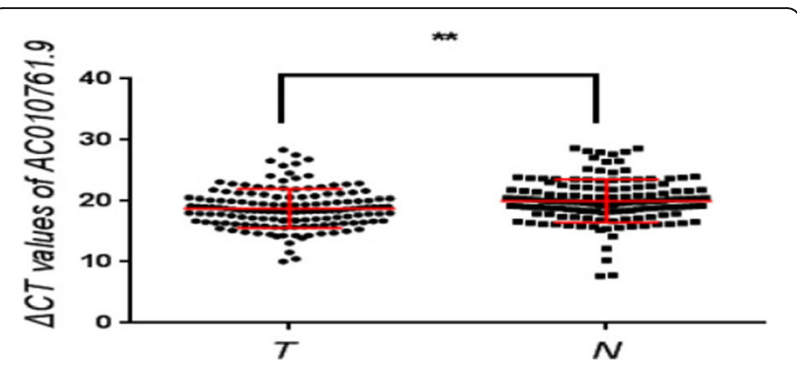

Fig. $\mathbf{2}$ LncRNA AC010761.9 was over-expressed in GA tissues by quantified RT-PCR measurement. $T$ cancer tissues, $N$ matched non-cancer tissues. T versus $\mathrm{N}, p<0.01$. The data were from 145 cases of GA. The higher the $\Delta C \mathrm{C}$ values, the lower the IncRNA AC010761.9 expression. Data were obtained from three independent tests

Relationships between the level of IncRNA AC010761.9 expression and serum and IHC GA markers

As depicted in Table 1 and Additional file 1: Table S1, the relationships between the level of IncRNA AC010761.9 expression and serum CEA, CA19-9, and AFP concentrations and the ten IHC markers showed that IncRNA AC010761.9 expression was related with the serum carbohydrate antigen (CA19-9) and carcinoembryonic antigen (CEA) concentrations $(p=0.026$ and $p=0.037$, respectively), but not related to serum AFP concentrations and ten IHC markers (Table 1 and Additional file 1: Table S1).

\section{Relationships between the level of IncRNA AC010761.9} and TRAF4 mRNA expression in GA tissues and cell lines TRAF4 has been observed to participate in several human cancer developments $[11,12]$. The TRAF4 gene is speculated to be the potential sense strand gene of lncRNA AC010761.9, thus the level of its expression in 78 GA tissues and matched non-GA tissues was also investigated and related to the level of lncRNA AC010761.9

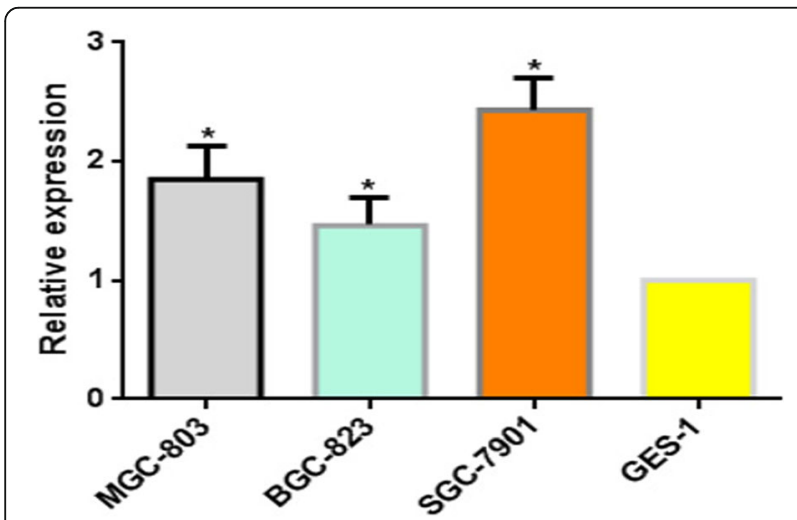

Fig. 3 LncRNA AC010761.9 was over-expressed in GA cell lines. The data were from three GA cell lines (MGC-803, BGC-823, and SGC-7901) and control cells (normal gastric cell line [GES-1]). GA cells versus control cells (all $p<0.05$ ). The higher the $\Delta$ Ct values, the lower the IncRNA AC010761.9 expression. Data were obtained from three independent tests
Table 2 Relationships between IncRNA AC010761.9 expression ( $\Delta$ Ct value) and patient clinical pathologic factors analyzed by univariate and multivariate

\begin{tabular}{lll}
\hline Characteristics & $\begin{array}{l}\text { Univariate } \\
p \text { value }\end{array}$ & $\begin{array}{l}\text { Multivariate } \\
p \text { value }\end{array}$ \\
\hline Diameter & 0.028 & 0.255 \\
Differentiation & 0.047 & 0.015 \\
Invasion & 0.269 & 0.196 \\
Lymphatic metastasis & 0.597 & 0.777 \\
Venous invasion & 0.808 & 0.063 \\
Perineural invasion & 0.399 & 0.222 \\
Location & 0.621 & 0.473 \\
Age & 0.162 & 0.078 \\
Sex & 0.620 & 0.043 \\
\hline
\end{tabular}

expression in the same tissues. As depicted in Fig. 4, the expression of TRAF4 mRNA in 54 of 78 GA tissues was higher than the matched non-GA tissues with a mean over-expressed rate of $69.2 \%(p<0.05)$ and an elevated fold up to 10.04. The results from Pearson correlation analyses showed that the level of lncRNA AC010761.9 expression was to some degree a positive correlation to the expression of the potentially associated gene (TRAF4) mRNA in GA tissues $(r=0.385, p<0.01)$ (Fig. 5). Additionally, the expression levels of lncRNA AC010761.9 and TRAF4 mRNA among the three GA cell lines (BGC-823, SGC-7901, and MGC-803) also exhibited similarly overexpressed trend compared with those in GES-1 cells.

\section{Discussion}

Currently, a number of studies have shown that abnormal expression of lncRNAs is associated with cancer progression and prognosis, such as $\mathrm{T}$ staging, $\mathrm{N}$ staging, tumor size, invasion, and survival $[14,15]$. Therefore, lncRNAs

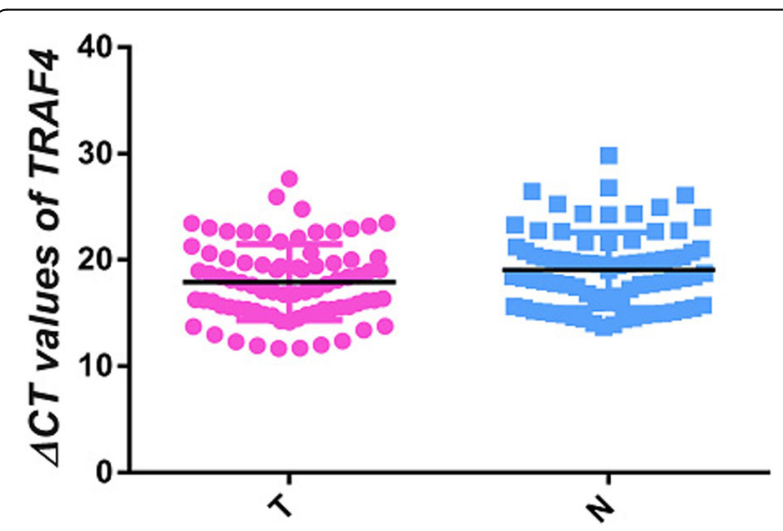

Fig. 4 TRAF4 mRNA was over-expressed in GA tissues. T cancer tissues, $N$ matched non-cancer tissues. T versus $N, p<0.05$. The data were from 78 cases of GA. The higher the $\Delta C t$ values, the lower the TRAF4 mRNA expression. Data were obtained from three independent tests 


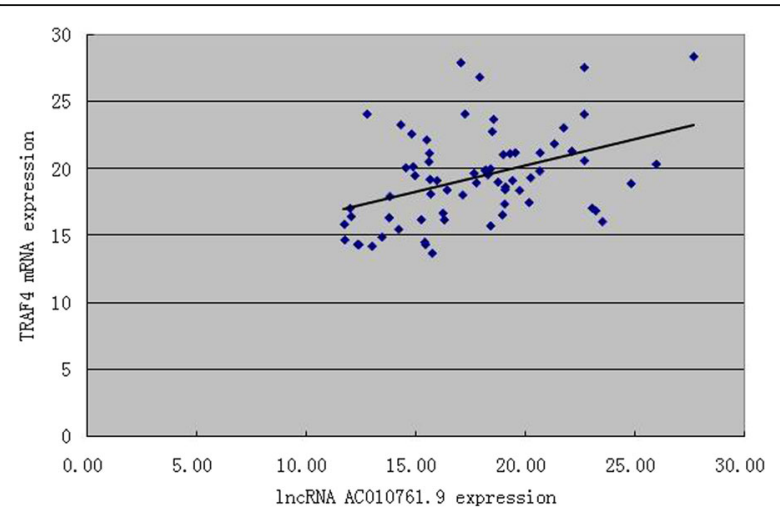

Fig. 5 The expression of IncRNA AC010761.9 showed a positive correlation with the expression of TRAF4 mRNA. $r=0.385$ and $p<0.01$ were obtained by Pearson correlation analysis

are regarded as a new biomarker and therapeutic target for various human cancers. Gastric cancer is a typical cancer, which frequently has dysregulated expression of lncRNAs. Abnormal expression of lncRNAs has been identified to play the roles of oncogenes or inhibiting genes exacerbating or attenuating gastric cancer development $[16,17]$. In the current study, we also identified a lncRNA: LncRNA AC010761.9 may be GA-related.

LncRNA AC010761.9 is a RNA located on human chromosome 17 with a total length of $521 \mathrm{bp}$. LncRNA AC010761.9 does not have the ability of coding for protein, which is a new IncRNA and unreported in GA or other cancers. The level of this lncRNA expression was significantly up-regulated in GA tissues compared to normal tissues and was also significantly up-regulated in MGC803, BGC823, and SGC7901 cells. Over-expressed lncRNA AC010761.9 was related with tumor size and degree of GA differentiation, as well as related to serum CEA and CA199 levels of the digestive system tumor markers.

Tumor size and the degree of differentiation are associated with GA progression. Therefore, a lncRNA that is linked to these two pathologic factors may have important clinical value. CEA and CA19-9 are the two most widely confirmed and used serum digestive cancer markers worldwide [18]. If a lncRNA is associated with these two markers, the lncRNA may have the potential to be combined with CEA and CA19-9 levels and used for GA diagnosis or treatment monitoring.

Because the IncRNA itself does not encode the protein, but functions in the regulation of gene expression, we further investigated the expression level of the potentially associated gene (TRAF4 gene) of this lncRNA in GA tissues and cell lines and found that the level of TRAF4 mRNA was significantly up-regulated compared to normal tissues and was also higher expression in the three GA cell lines (MGC803, BGC823, and SGC7901) than normal gastric epithelial cells (GES-1). The level of lncRNA AC010761.9 expression in GA tissues and cell lines showed a positive correlation or similarly upregulated trend with the potentially associated gene TRAF4 mRNA level. Therefore, lncRNA AC010761.9 could have the potential to play a biological role in GA by regulating the expression of TRAF4. Because the samples used in the current study were not sufficiently large and the relationship between the level of lncRNA AC010761.9 and TRAF4 mRNA expression value was lower, further investigations are needed to confirm this point, including the use of a larger tissue sample size and gene or siRNA transfection techniques to increase or decrease lncRNA AC010761.9 expression to observe the change in expression of TRAF4 mRNA.

TRAF4 is one of the members of the TRAF family of proteins [19]. It has been confirmed that TRAF4 is overexpressed in several different human cancers $[19,20]$. TRAF4 is also known to play a major role in embryonic development, cell polarity, and apoptosis and regulation of reactive oxygen species (ROS) production [21]. TRAF4 and $\beta$-catenin exhibit a mutual relationship of interaction [22]. $\beta$-catenin was first recognized as an adhesion factor, and later studies showed that $\beta$-catenin is also a multifunctional protein [23], which is widely found in various types of cells, such as endothelial cells, fibroblasts, and osteoblasts and is involved in the regulation of cell proliferation, differentiation, and apoptosis. An abundance of data has shown that $\beta$-catenin is closely related with malignant tumor development and invasion and is also transferrelated [24]. $\beta$-catenin has been shown to have main functions on mediating cell adhesion and gene expression [25]. Additionally, $\beta$-catenin plays an important role in increased oncogene c-myc gene expression, leading to carcinogenesis [26]. TRAF4 is identified to function in enhancing $\beta$ catenin-related transcription and protecting the $\beta$-catenin protein to be degraded by the p53 gene-mediated degradation pathway. TRAF4 can also regulate the activation of NF-kB [27]. NF-kB activation can promote cell growth, thus many anti-tumor drugs target on NF-kB, which is regarded as the treated target of many different cancers [28]. TRAF4 can also regulate the formation of reactive oxygen species and is associated with JNK activation [29]. All these findings suggest that lncRNA AC010761.9 was identified as GA-related lncRNA, which may be associated with an increase in TRAF4 mRNA expression.

\section{Conclusion}

In conclusion, the results from the present study indicated that IncRNA AC010761.9 is significantly up-regulated in GA tissues and GA cell lines. The expression of lncRNA AC010761.9 and TRAF4 in gastric carcinoma 
was positively correlated, which suggests that lncRNA AC010761.9 may play a biological role in the development and progression of GA possibly by regulating the expression of TRAF4. The expression level of lncRNA AC010761.9 was significantly correlated with the degree of tumor differentiation and tumor size and also correlated with serum CEA and CA199 levels of digestive system tumor markers, all of which indicate lncRNA AC010761.9 could be used as a new biomarker and a new target for the treatment of GA.

\section{Additional files}

Additional file 1: Table S1. Relationship between IncRNA AC010761.9 expression ( $\Delta$ Ct value) and GA immunohistochemical markers (DOCX $15 \mathrm{~kb}$ )

\section{Acknowledgements}

We thank Dr. Xiaohuang Tu and Dr. Yu Wang, Department of Genera Surgery, for their assistance in guiding the samples collected in this study.

\section{Funding}

The study was supported by the Innovation Team Foundation of Fuzhou General Hospital (2014CXTD04) for Lie Wang.

\section{Availability of data and materials}

Please contact the author for data requests.

\section{Authors' contributions}

$\mathrm{QH}$ and LW conceived and designed the experiments. ZW and KW performed the experiments and analyzed the data. YD, XO, FZ, and WW contributed the samples collected. $\mathrm{QH}$ and $\mathrm{ZW}$ wrote the paper. All authors read and approved the final manuscript.

\section{Ethics approval and consent to participate}

The study was approved by the Committees for the Ethical Review of Research involving human subjects from Fuzhou General Hospital.

\section{Consent for publication}

All authors have reviewed the manuscript and approve it for publication. We claim that none of the materials in this article has been published or is under consideration for publication elsewhere.

\section{Competing interests}

The authors declare that they have no competing interests.

\section{Publisher's Note}

Springer Nature remains neutral with regard to jurisdictional claims in published maps and institutional affiliations.

\section{Author details \\ ${ }^{1}$ Department of Experimental Medicine, Fuzong Clinical Medical College, Fujian Medical University, Fuzhou, China. ${ }^{2}$ Department of Experimental Medicine, Fuzhou General Hospital, 156 North Xi-er Huan Road, Fuzhou, Fujian 350025, China. ${ }^{3}$ Department of General Surgery, Fuzong Clinical Medical College, Fujian Medical University, Fuzhou, China. ${ }^{4}$ Department of General Surgery, Fuzhou General Hospital, Fuzhou, Fujian 350025, China. ${ }^{5}$ Department of Clinical Laboratory of the 92th Hospital of PLA, North Binjiang Road, Nanping City, Fujian 353000, China.}

Received: 19 May 2017 Accepted: 4 December 2017

Published online: 02 March 2018

\section{References}

1. Siegel R, Naishadham D, Jemal A. Cancer statistics, 2012. CA Cancer J Clin. 2012;62:10-29.
2. Liu MT, Chen MK, Huang CC, Huang CY. Prognostic value of molecular markers and implication for molecular targeted therapies in nasopharyngeal carcinoma: nn update in an era of new targeted molecules development. World J Oncol. 2015;6:243-61.

3. Jiang C, Li X, Zhao H, Liu H. Long non-coding RNAs: potential new biomarkers for predicting tumor invasion and metastasis. Mol Cancer. 2016;15:62.

4. Wang KC, Chang HY. Molecular mechanisms of long noncoding RNAs. Mol Cell. 2011;43:904-14.

5. Qi P, Du X. The long non-coding RNAs, a new cancer diagnostic and therapeutic gold mine. Mod Pathol. 2013;26:155-65.

6. Ponting CP, Oliver PL, Reik W. Evolution and functions of long noncoding RNAs. Cell. 2009;136:629-41.

7. Mei D, Song H, Wang K, Lou Y, Sun W, Liu Z, et al. Up-regulation of SUMO1 pseudogene 3 (SUMO1P3) in gastric cancer and its clinical association. Med Oncol. 2013:30:709.

8. Yang F, Bi J, Xue X, Zheng L, Zhi K, Hua J, et al. Up-regulated long noncoding RNA H19 contributes to proliferation of gastric cancer cells. FEBS J. 2012;279:3159-65.

9. Yang $F$, Xue $X, B i J$, Zheng $L$, Zhi K, Gu Y, et al. Long noncoding RNA CCAT1, which could be activated by c-Myc, promotes the progression of gastric carcinoma. J Cancer Res Clin Oncol. 2013;139:437-45.

10. Cao WJ, HL W, He BS, Zhang YS, Zhang ZY. Analysis of long non-coding RNA expression profiles in gastric cancer. World J Gastroenterol. 2013;19:3658-64.

11. Yang J, Wei D, Wang W, Shen B, Xu S, Cao Y. TRAF4 enhances oral squamous cell carcinoma cell growth, invasion and migration by Wnt-betacatenin signaling pathway. Int J Clin Exp Pathol. 2015;8:11837-46.

12. Wang A, Wang J, Ren H, Yang F, Sun L, Diao K, et al. TRAF4 participates in Wnt/beta-catenin signaling in breast cancer by upregulating beta-catenin and mediating its translocation to the nucleus. Mol Cell Biochem. 2014; 395(1-2):211-9.

13. Dang $Y$, Lan $F$, Ouyang $X$, Wang $K$, Lin $Y, Y u Y$, et al. Expression and clinical significance of long non-coding RNA HNF1A-AS1 in human gastric cancer. World Journal of Surgical Oncology. 2015;13:302.

14. Zhao J, Liu Y, Huang G, Cui P, Zhang W, Zhang Y. Long non-coding RNAs in gastric cancer: versatile mechanisms and potential for clinical translation. Am J Cancer Res. 2015;5(3):907-27.

15. Kladi-Skandali A, Michaelidou K, Scorilas A, Mavridis K. Long noncoding RNAs in digestive system malignancies: a novel class of cancer biomarkers and therapeutic targets? Gastroenterol Res Pract. 2015;2015:319861.

16. Sun J, Song Y, Chen X, Zhao J, Gao P, Huang X, et al. Novel long noncoding RNA RP11-119F7.4 as a potential biomarker for the development and progression of gastric cancer. Oncol Lett. 2015;10:115-20.

17. Yang Q, Zhang RW, Sui PC, He HT, Ding L. Dysregulation of non-coding RNAs in gastric cancer. World J Gastroenterol. 2015;21:10956-81.

18. Shimada H, Noie T, Ohashi M, Oba K, Takahashi Y. Clinical significance of serum tumor markers for gastric cancer: a systematic review of literature by the Task Force of the Japanese Gastric Cancer Association. Gastric Cancer. 2014;17:26-33.

19. Wang A, Wang J, Sun $L$, Jin J, Ren $H$, Yang F, et al. Expression of tumor necrosis factor receptor-assicated factor 4 correlates with expression of girdin and promotes nuclear translocation of girdin in breast cancer. $\mathrm{Mol}$ Med Rep. 2015:11:3635-41.

20. Vranic S, Marchio C, Castellano I, Botta C, Scalzo MS, Bender RP, et al. Immunohistochemical and molecular profiling of histologically defined apocrine carcinomas of the breast. Hum Pathol. 2015;46:1350-9.

21. Arthur JF, Shen Y, Gardiner EE, Coleman L, Murphy D, Kenny D, et al. TNF receptor-associated factor 4 (TRAF4) is a novel binding partner of glycoprotein Ib and glycoprotein VI in human platelets. J Thromb Haemost. 2011;9:163-72.

22. Yang K, Wang F, Han JJ. TRAF4 promotes the growth and invasion of colon cancer through the Wnt/beta-catenin pathway. Int J Clin Exp Pathol. 2015:8:1419-26.

23. Barghout SH, Zepeda N, Xu Z, Steed H, Lee CH, Elevated FY. Beta-catenin activity contributes to carboplatin resistance in $\mathrm{A} 2780 \mathrm{cp}$ ovarian cancer cells. Biochem Biophys Res Commun. 2015;468:173-8.

24. Lee KB, Ye S, Park MH, Park BH, Lee JS, Kim SM. p63-Mediated activation of the beta-catenin/c-Myc signaling pathway stimulates esophageal squamous carcinoma cell invasion and metastasis. Cancer Lett. 2014:353:124-32.

25. Lyashenko N, Winter M, Migliorini D, Biechele T, Moon RT, Hartmann C. Differential requirement for the dual functions of beta-catenin in embryonic stem cell self-renewal and germ layer formation. Nat Cell Biol. 2011;13:753-61. 
26. Bozkaya G, Korhan P, Cokakli M, Erdal E, Sagol O, Karademir S. Cooperative interaction of MUC1 with the HGF/c-Met pathway during hepatocarcinogenesis. Mol Cancer. 2012;11:64.

27. Esparza EM, Arch RH. TRAF4 functions as an intermediate of GITR-induced NF-kappaB activation. Cell Mol Life Sci. 2004;61:3087-92.

28. Safe S, Kasiappan R. Natural products as mechanism-based anticancer agents: sp transcription factors as targets. Phytother Res. 2016;30:1723-32.

29. Abell AN, Johnson GL. MEKK 4 is an effector of the embryonic TRAF4 for JNK activation. J Biol Chem. 2005;280:35793-6.

Submit your next manuscript to BioMed Central and we will help you at every step:

- We accept pre-submission inquiries

- Our selector tool helps you to find the most relevant journal

- We provide round the clock customer support

- Convenient online submission

- Thorough peer review

- Inclusion in PubMed and all major indexing services

- Maximum visibility for your research

Submit your manuscript at www.biomedcentral.com/submit
Biomed Central 